\title{
Total Blood Lymphocyte Count Alteration During and After Pregnancy
}

\author{
Gökçen ÖRGÜL ${ }^{1}$, Burcu SOYAK ${ }^{1}$, Oytun PORTAKAL ${ }^{2}$, Meral BEKSAÇ³, M. Sinan BEKSAÇ¹ \\ Ankara, Turkey
}

\section{ABSTRACT}

OBJECTIVE: To investigate the impact of gestational changes on blood lymphocyte count in healthy pregnancies.

STUDY DESIGN: This retrospective study is consisted of 108 consecutive normal pregnancies who delivered at our department in December 2015. High-risk pregnancies with poor neonatal outcome and pregnancies with maternal disorders which may affect lymphocyte counts were excluded from the study. "Complete blood count" results of the patients were obtained from the computerized data base system of Hacettepe University Hospital. Blood samples of patients which were withdrawn a) prior to pregnancy (1-6 months before getting pregnant), b) during pregnancy $\left(11-14^{\text {th }}\right.$ gestational weeks) and c) post-partum first day were used in this study.

RESULTS: The mean blood lymphocyte count was $2049.07( \pm 758.69)$ in patients before their pregnancies. The mean lymphocyte count decreased to 1850.93 and 1625 during pregnancy and after delivery respectively. A statistically significant decrease was found between three periods (before, during, and postpartum $1^{\text {st }}$ day) (p:0.003).

CONCLUSION: We have shown a significant decrease in total lymphocyte levels during pregnancy, consistent with the data presented in the literature. Pregnancy and related hormones have a negative impact on total blood lymphocyte level.

Keywords: Pregnancy, Lymphocyte count, Hematocrit

Gynecol Obstet Reprod Med 2017;23(1):11-13

\section{Introduction}

Semi-allograft fetus developing in uterus complicates the immune response during pregnancy. Trophoblasts and maternal cells interact continuously with each other at the maternofetal interface (1). Immunosuppression is selectively necessary for implantation and fetal growth. However, all of these steps also need the increased immunomodulatory functions of

\footnotetext{
${ }^{1}$ Department of Obstetrics and Gynecology and ${ }^{2}$ Department of Biochemistry Hacettepe University School of Medicine, Ankara

${ }^{3}$ Department of Hematology, Ankara University School of Medicine, Ankara

Address of Correspondence: Gökçen Örgül

Hacettepe University Faculty of Medicine, Department of Obstetrics and Gynecology Division of Perinatology, Ankara, Turkey gokcenorgul@gmail.com

Submitted for Publication: $\quad$ 09.09.2016 Accepted for Publication: $\quad 28.09 .2016$
}

\begin{tabular}{|c|c|}
\hline & Access this article online \\
\hline $\begin{array}{c}\text { Quick Response Code: } \\
\text { ans }\end{array}$ & Website: www.gorm.com.tr \\
\cline { 2 - 3 } & DOI:10.21613/GORM.2016.633 \\
\hline
\end{tabular}

How to cite this article: Örgül G. Soyak B. Portakal O. Beksac M. Beksaç MS. Total Blood Lymphocyte Count Alteration During and After Pregnancy. Gynecol Obstet Reprod Med 2017;23(1):11-13 maternal immune cells for placentation. In summary, the immune response in pregnancy has both stimulatory and suppressive functions for a successful pregnancy outcome (2).

Blood levels of nucleated cells undergo important changes during pregnancy due to hormonal effects. Lymphocyte levels decrease during pregnancy and start to increase after delivery (3). The lymphocyte subgroup distribution in the decidua also alters and the most important change occurs in endometrial natural killer (NK) cells. Decidual NK cells become predominant immune cells in pregnant uterus (4). Both blood lymphocyte counts and tissue-specific changes are necessary for maintaining the pregnancy.

In this study, we aimed to demonstrate the impact of early gestational changes on blood lymphocyte count in healthy pregnancies.

\section{Material and Method}

This retrospective study is consisted of 108 consecutive pregnancies who delivered at our department in December 2015. High-risk pregnancies with poor neonatal outcome and pregnancies with maternal disorders which may affect lymphocyte counts were excluded from the study. "Complete blood count" results of the patients were obtained from the computerized data base system of Hacettepe University Hospital. Blood samples of patients which were withdrawn a) prior to pregnancy (1-6 months before getting pregnant), b) 
during pregnancy (11-14 ${ }^{\text {th }}$ gestational weeks) and c) post-partum first day were used in this study. Patients with missing data were also excluded from the study. Complete blood count calculation during these period is mandatory in our routine practice within the framework of Hacettepe University "antenatal care program". This study was carried out with the permission of "Hacettepe University Ethics Board Commission" (no: GO 16/371-13).

Blood samples were drawn from the antecubital vein into K2-EDTA tubes and tested in the same day. Hematological parameters for complete blood count were determined using a UniCel DXH800 fully automated cell counter (Beckman Coulter, Inc., US). VCS technology was used to determine total lymphocyte levels.

All statistical analyses were performed using SPSS version 17.3. The descriptive results were given as means and standard deviation (SD). Data were compared by using pairwise comparisons and multivariate tests. The level of significance was set at 0.05 .

\section{Results}

The total number of blood samples included in the study was 324, obtained from 108 patients. The mean age of our study group was 31.03 (range between 20 and 42 years old).

The mean blood lymphocyte count was 2049.07 cells $/ \mu \mathrm{L}$ in patients before their pregnancies. The mean lymphocyte count decreased to 1850.93 cells $/ \mu \mathrm{L}$ and 1625 cells $/ \mu \mathrm{L}$ during pregnancy (in-between 11-14 ${ }^{\text {th }}$ gestational weeks) and after delivery (post-partum first day), respectively (Table 1). Lymphocyte count decreased approximately 198.15 cells $/ \mu \mathrm{L}$ during pregnancy from its highest level at pre-pregnancy. The mean difference was 225.93 cells/ $\mu \mathrm{L}$ between pregnancy and postpartum $1^{\text {st }}$ day. A statistically significant decrease (p: 0.003 ) was found between these three periods by using pairwise comparisons. Figure 1 shows the distribution of lymphocyte levels during three periods.

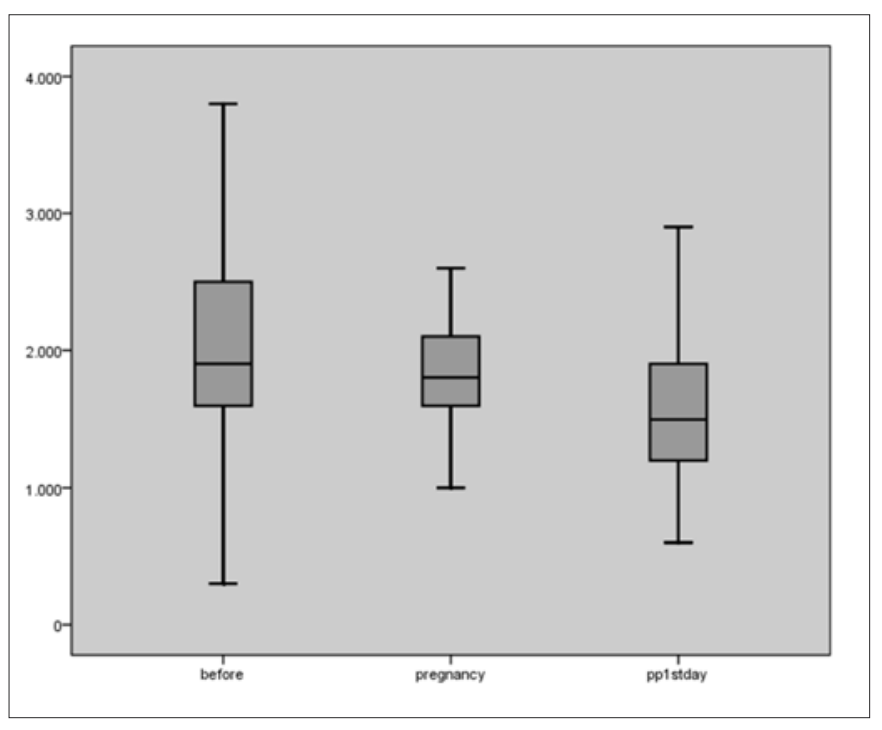

Figure 1: Distribution of lymphocyte levels during periods

We have also studied mean hematocrit levels during these three periods to exclude the effect of hemodilution (Table 2). The mean hematocrit levels were $36.77 \%, 35.94 \%$, and 31.50 $\%$ in terms of prior to pregnancy, during pregnancy and postpartum $1^{\text {st }}$ day, respectively. Mean hematocrit level declined statistically insignificantly during pregnancy (p:0.25). On the other hand, mean hematocrit levels decreased statistically significantly after delivery $\left(11-14^{\text {th }}\right.$ gestational weeks versus post-partum first day) (p:0.001).

\section{Discussion}

Pregnancy has various effects on hematological cell counts and their functions. Increased plasma volume and decreased iron stores cause dilutional anemia, while altered coagulation induces gestational thrombocytopenia (5). In our study, hematocrit decrease during early pregnancy $\left(11-14^{\text {th }}\right.$ gestational weeks) was not statistically significant but postpartum $1^{\text {st }}$ day hematocrit levels were found to be decreased most probably due to late pregnancy hematological/metabolic changes and blood lost during delivery. Specious lymphocyte decrease due

Table 1: Mean lymphocyte levels of each group

Mean blood lymphocyte

count (cells/ $\mu \mathrm{L})$
Std. deviation

2049.07
1850.93
1625

758.687

501.865

581.51

108

108

108

Table 2: Mean hematocrit levels of each group

\begin{tabular}{|c|c|c|c|}
\hline & Mean hematocrit (\%) & Std. deviation & $\mathrm{n}$ \\
\hline Prior to pregnancy & 36.77 & 4.24 & 108 \\
\hline Pregnancy & 35.94 & 3.31 & 108 \\
\hline Postpartum $1^{\text {st }}$ day & 31.51 & 3.87 & 108 \\
\hline
\end{tabular}


to hemodilution was excluded with these findings in our study. White blood cell (WBC) levels also change during pregnancy and postpartum period (6). The enhancement of WBC count is predominantly through increased neutrophil levels and this left shift seems to be a protective mechanism for both fetus and mother (7).

It has been well documented that lymphocyte count declines during pregnancy and reaches its normal level after delivery $(3,8,9)$. We have shown a significant decrease in total lymphocyte levels during pregnancy, consistent with the data given in the literature. Some studies were carried out to execute the distribution of lymphocyte subsets during pregnancy. T and B lymphocytes, NK cells, and T-cell subgroup proportion do not change is the main consensus of these studies $(6,9)$. We did not analyze alteration in the lymphocyte subsets in our study.

Pregnancy has different effects on thymic mass and activity. It is a well-known fact that thymus becomes smaller during pregnancy and total thymocytes also decline in the tissue. All of these physiological changes result in a significant decrease in total T-cell number $(10,11)$. Lymphocyte- dependent cytotoxicity is activated by a2V-ATPase expression on the cell surface. This enzyme has an important function in T-cell and NK-cell differentiation and maturation. Pregnancy has a positive effect on a2V-ATPase, especially in the thymus, which seems to be the reason of total blood lymphocyte count changes (12).

Changes in lymphocyte level at puerperium have been investigated in a limited number of studies. Investigators claimed that neutrophil and leukocyte levels start to increase, even in the first day after labour (13). Also, Kühner at al. demonstrated enhanced lymphocyte levels in the first week after labour (9). We have shown that lymphocytes decrease after delivery; however, our data is limited to post-partum $1^{\text {st }}$ day. This seems to be a result of acute blood loss after birth as it is expected.

In conclusion, there is a significant decrease in total lymphocyte levels during pregnancy. Pregnancy and related hormones have a negative impact on total blood lymphocyte count. Well-designed future studies are necessary to understand the impact of pregnancy on lymphocytes.

\section{References}

1. Robertson SA. Immune regulation of conception and embryo implantation-all about quality control? J Reprod Immunol 2010;85(1):51-7.
2. Dekel N, Gnainsky Y, Granot I, Mor G. Inflammation and implantation. Am J Reprod Immunol 2010;63(1):17-21.

3. Valdimarsson H, Mulholland C, Fridriksdottir V, Coleman DV. A longitudinal study of leucocyte blood counts and lymphocyte responses in pregnancy: a marked early increase of monocyte-lymphocyte ratio. Clin Exp Immunol 1983;53(2):437-43.

4. Tilburgs T, Claas FH, Scherjon SA. Elsevier Trophoblast Research Award Lecture: Unique properties of decidual T cells and their role in immune regulation during human pregnancy. Placenta 2010;31 Suppl:S82-6.

5. Milman N, Bergholt T, Byg KE, Eriksen L, Hvas AM. Reference intervals for haematological variables during normal pregnancy and postpartum in 434 healthy Danish women. Eur J Haematol 2007;79(1):39-46.

6. Iwatani Y, Amino N, Tachi J, Kimura M, Ura I, Mori M, et al. Changes of lymphocyte subsets in normal pregnant and postpartum women: postpartum increase in $\mathrm{NK} / \mathrm{K}$ (Leu 7) cells. Am J Reprod Immunol Microbiol 1988; 18(2):52-5.

7. Akinbami AA, Ajibola SO, Rabiu KA, Adewunmi AA, Dosunmu AO, Adediran A, et al. Hematological profile of normal pregnant women in Lagos, Nigeria. International Journal of Women's Health 2013;5:227-32.

8. Lurie S, Rahamim E, Piper I, Golan A, Sadan O. Total and differential leukocyte counts percentiles in normal pregnancy. Eur J Obstet Gynecol Reprod Biol 2008;136 (1):16-9.

9. Kühnert M, Strohmeier R, Stegmüller M, Halberstadt E. Changes in lymphocyte subsets during normal pregnancy. European Journal of Obstetrics \& Gynecology and Reproductive Biology 1998;76(2):147-51.

10. Rijhsinghani AG, Bhatia SK, Tygrett LT, Waldschmidt TJ. Effect of pregnancy on thymic T cell development. Am J Reprod Immunol 1996;35(6):523-8.

11. Kendall MD, Clarke AG. The thymus in the mouse changes its activity during pregnancy: a study of the microenvironment. Journal of anatomy 2000;197(03):393411.

12. Jaiswal M, Mallers T, Chaouat G, Gilman-Sachs A, Beaman K. Pregnancy alters T-cell development in the mouse thymus. J Immunol 2012;188(1 Supplement): 115.11

13. Onwukeme KE. Puerperal Haematological Indices in the Nigerian. African Journal of Medicine and Medical Sciences 1992;21(2):51-5. 